\title{
STUDI EKSPERIMENTAL PENINGKATAN KEDALAMAN POTONG PROSES BUBUT SLENDER BAR DENGAN MENGGUNAKAN FOLLOWER REST DAN VARIASI SUDUT POTONG UTAMA
}

\author{
Peniel I. Gultom ${ }^{(1)}$, Masrurotul Ajiza ${ }^{(2)}$ \\ ${ }^{1)}$ Prodi Teknik Mesin DIII, Fakultas Teknologi Industri, Institut Teknologi Nasional Malang \\ ${ }^{2}$ Prodi Teknik Geodesi, Fakultas Teknik Sipil dan Perencanaan, Institut Teknologi Nasional Malang
}

\begin{abstract}
Abstrak, Proses bubut adalah salah satu proses manufaktur yang penting dan banyak digunakan dalam industri besar, kecil dan bahkan mikro. Masukan material dan pengaturan parameter mesin bubut mempengaruhi efisiensi proses dan kualitas hasil. Persaingan di industri manufaktur menuntut produk dengan kualitas tinggi dan produktivitas tinggi juga. Parameter pemesinan seperti sudut potong, kecepatan potong dan kedalaman potong menentukan besarnya laju pengerjaan material atau material removal rate (MRR) dari proses bubut. Penentuan kedalaman pemotongan secara berlebihan justru akan menurunkan produktivitas karena adanya suatu produk yang harus dikerjakan ulang (reworked).

Proses bubut lead screw, broaching cutter, axle shaft, propeller shaft dan shaft lainnya yang dalam proses pengerjaannya membutuhkan steady rest maupun follower rest sangat sulit dilakukan karena pada umumnya benda kerja tersebut memiliki tingkat kekakuan yang rendah.

Penelitian ini dilakukan pada proses bubut dengan benda kerja slender bar. Hal ini disebabkan pada kenyataan dilapangan proses pembubutan slender bar merupakan proses bubut yang paling sulit untuk mendapatkan hasil yang presisi. Melihat kondisi tersebut di atas maka permasalahan yang timbul adalah bagaimana menentukan sudut potong utama, kecepatan potong dan kedalaman potong pada proses bubut dengan benda kerja slender bar yang akan meningkatkan kualitas hasil bubut dan tingkat presisi pada produk. Luaran yang diperoleh merupakan parameter proses pembubutan slender bar menggunakan follower rest.
\end{abstract}

Kata Kunci: Kecepatan Potong, Kedalaman Potong, Slender Bar, Sudut Potong Utama

\section{PENDAHULUAN}

Proses bubut adalah salah satu proses manufaktur yang penting dan banyak digunakan dalam industri besar, kecil dan bahkan mikro. Masukan material dan pengaturan parameter mesin bubut mempengaruhi efisiensi proses dan kualitas hasil. Persaingan di industri manufaktur menuntut produk dengan kualitas tinggi dan produktivitas tinggi juga. Harga yang kompetitif dapat dicapai dengan meningkatkan laju pengerjaan material saat memproduksi suatu produk tertentu agar produk yang dihasilkan memiliki daya saing yang tinggi.

Parameter pemesinan seperti kecepatan potong dan kedalaman potong menentukan besarnya laju pengerjaan material atau material removal rate (MRR) dari proses bubut. Penentuan kedalaman pemotongan secara berlebihan justru akan menurunkan produktivitas karena adanya suatu produk yang harus dikerjakan ulang (reworked) bahkan diganti karena terjadinya cacat pada permukaan hasil pemotongan.
Proses bubut lead screw, broaching cutter, axle shaft, propeller shaft dan shaft lainnya yang dalam proses pengerjaannya membutuhkan steady rest maupun follower rest sangat sulit dilakukan karena pada umumnya benda kerja tersebut memiliki tingkat kekakuan yang rendah.

Steady rest dan follower rest merupakan peralatan bantu untuk menopang benda kerja pada proses bubut shaft. Pada umumnya follower rest lebih sering digunakan karena memasang maupun melepas benda kerja lebih cepat bila dibandingkan dengan steady rest.

Penelitian dilakukan pada proses bubut dengan benda kerja slender bar. Hal ini disebabkan pada kenyataan dilapangan proses pembubutan slender bar merupakan proses bubut yang paling sulit untuk mendapatkan hasil yang presisi. Melihat kondisi tersebut di atas maka permasalahan yang timbul adalah bagaimana menentukan sudut potong utama, kecepatan potong dan kedalaman potong pada proses bubut dengan benda kerja slender bar 
yang akan meningkatkan kualitas hasil bubut dan tingkat presisi pada produk. Luaran yang diperoleh merupakan parameter proses pembubutan slender bar menggunakan follower rest.

\section{METODE}

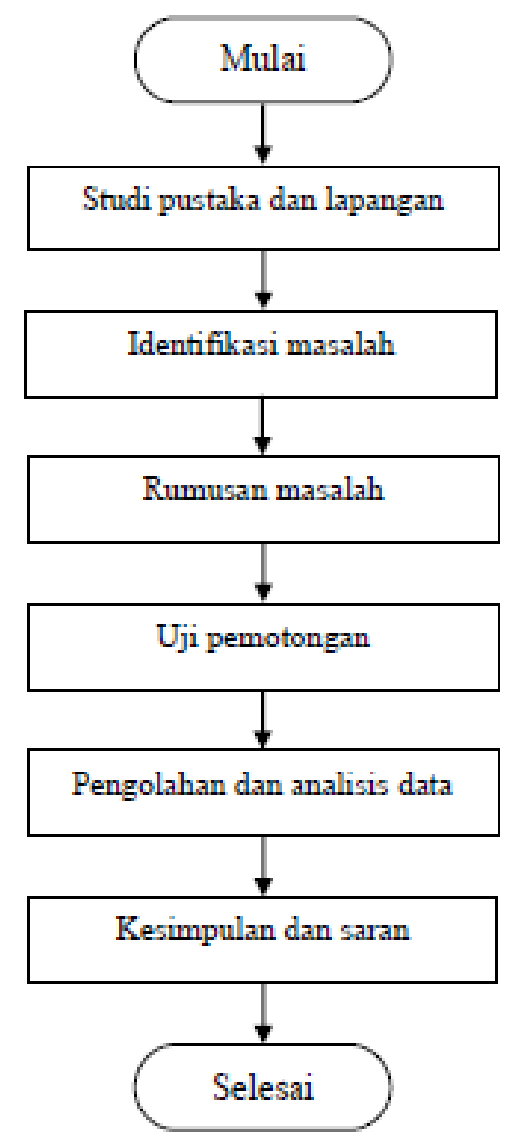

Gambar 1. Diagram Alir Penelitian

Langkah-langkah atau tahapan penelitian yang digunakan adalah sebagai berikut:

1. Survey lapangan, untuk mengamati proses bubut slender bar dan follower rest yang digunakan sebagai bahan pertimbangan dalam memodifikasinya

2. Studi Literatur, tujuannya untuk menemukan gap research dari penelitian sejenis sebelumnya. Sumber bacaan dapat berupa buku tesis, jurnal dan buku teks.

3. Rumusan masalah

4. Pengujian awal, pengujian awal dilakukan dengan uji eksitasi dan uji potong tanpa menggunakan peredam. Tujuannya untuk mendapatkan frekuensi pribadi sistem tanpa follower rest dan amplitudonya serta mengetahui batas stabilitas mesin tanpa peredam.

5. Analisis Data, data yang diperoleh di analisis dengan bantuan software untuk mengetahui batas stabilitas mesin pada masing-masing kondisi pemotongan untuk masing-masing kedalaman potong.

6. Pengujian, dilakukan uji eksitasi dan pemotongan dengan menggunakan peredam massa pegas. Uji pemotongan dilakukan dengan menggunakan follower rest dan tanpa follower rest.

8. Kesimpulan dan Saran

Data yang digunakan pada penelitian ini adalah merupakan data primer yang diperoleh dari hasil percobaan. Variabel yang digunakan pada penelitian ini adalah sebagai berikut:

- Variabel Proses

- Putaran mesin $520 \mathrm{rpm}$ dan $367 \mathrm{rpm}$

- Sudut potong $90^{\circ}$ dan $45^{\circ}$

- Gerak makan 0,07 mm/put dan 0,035 $\mathrm{mm} / \mathrm{put}$

- Variabel Respon

Kedalaman potong yang dapat dicapai (mulai dari 0,2 $\mathrm{mm}$ dan kelipatannya).

- Variabel Konstan

Variabel konstan yang didasarkan pada parameter proses pemotongan dengan menggunakan pahat insert jenis carbide TCMT 16T304 dimana material benda kerja low carbon steel ST-42.

\section{HASIL DAN PEMBAHASAN}

\section{A. Uji Pemotongan Dengan Proses Bubut}

Uji pemotongan dengan proses bubut merupakan suatu pengujian yang dilakukan untuk mengetahui sejauh mana pengaruh penggunaan follower rest dalam suatu proses pemotongan. Uji pemotongan pada percobaan ini dilakukan menjadi 2 kondisi yaitu tanpa menggunakan follower rest dan menggunakan follower rest dengan adjustable jaw horisontal dan adjustable jaw vertikal optimum.

Tujuan uji pemotongan ini adalah untuk mengetahui batas stabilitas proses bubut yang dinyatakan sebagai kedalaman potong. Semakin besar nilai kedalaman potong maka proses pemotongan akan semakin tidak stabil karena getaran (chatter) yang terjadi semakin besar. Oleh karena itu dalam pengujian ini akan 
diperoleh besar kedalaman potong saat terjadi chatter.

Kedalaman potong yang digunakan dalam percobaan ini secara bertahap mulai dari $0,2 \mathrm{~mm}$ dan kelipatannya. Terjadinya chatter ditandai dengan timbulnya suara bising yang berlebihan, meningkatnya kekasaran permukaan hasil pemotongan dan meningkatnya amplitudo getaran saat proses pemotongan berlangsung. Mesin bubut yang digunakan dalam penelitian ini adalah LA $530 \mathrm{x}$ 1100 seperti pada gambar 5.1 .

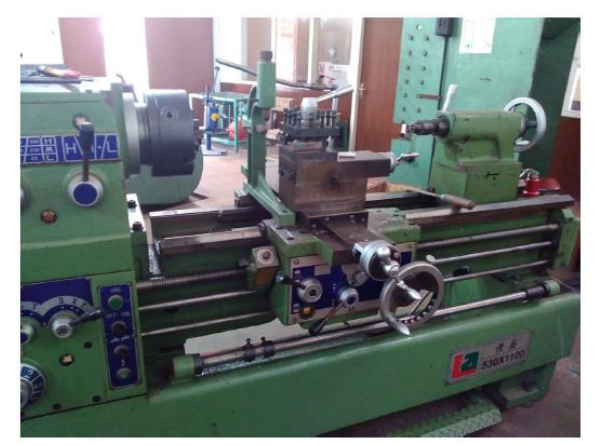

Gambar 2. Mesin Bubut LA 530 x 1100

\section{B. Uji pemotongan tanpa menggunakan follower rest}

1. Uji pemotongan $\mathrm{Kr}=45^{\circ}$

Gambar hasil pemotongan slender bar ST-42 dengan menggunakan pahat potong carbide insert dimana sudut potong utama $\mathrm{Kr}=45^{\circ}$ ditunjukkan pada gambar 3 sebagai tahap awal dan gambar 4 saat terjadinya chatter. Parameter proses pembubutan yang digunakan putaran mesin $367 \mathrm{rpm}$, gerak makan $0,035 \mathrm{~mm} /$ putaran.

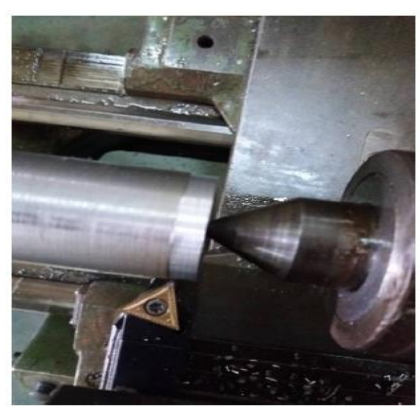

Gambar 3. Hasil Pemotongan Pada Kedalaman Potong $0,2 \mathrm{~mm}$

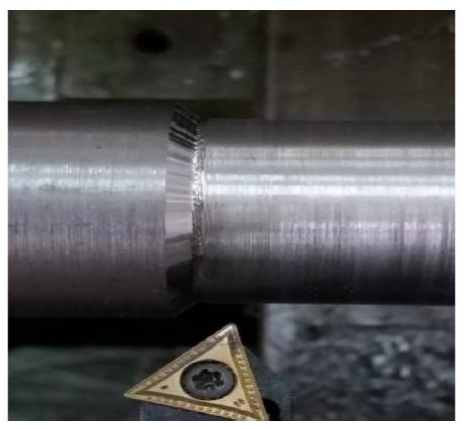

Gambar 4. Hasil Pemotongan Pada Edalaman Potong 2,2 mm, Terjadi Chatter

\section{Uji pemotongan $\mathrm{Kr}=90^{\circ}$}

Gambar hasil pemotongan slender bar ST-42 dengan menggunakan pahat potong carbide insert dimana sudut potong utama $\mathrm{Kr}=90^{\circ}$ ditunjukkan pada gambar 5 sebagai tahap awal proses bubut dan gambar 6 saat terjadi chatter. Parameter proses pembubutan yang digunakan putaran mesin $520 \mathrm{rpm}$, gerak makan $0,07 \mathrm{~mm} /$ putaran.

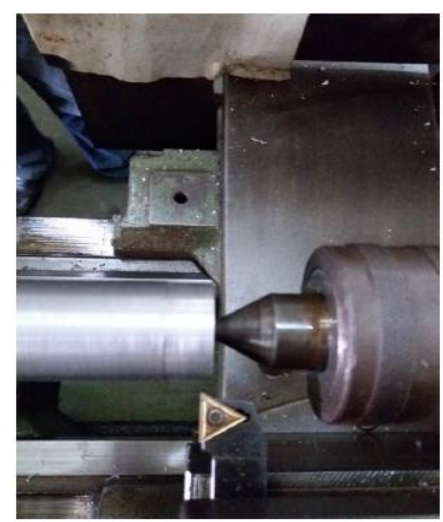

Gambar 5. Hasil Pemotongan Pada Kedalaman Potong $0,2 \mathrm{~mm}$

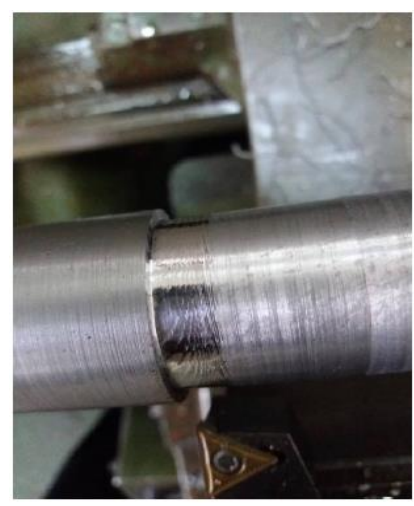

Gambar 6. Hasil Pemotongan Pada Kedalaman Potong 1,8 mm, Terjadi Chatter 


\section{Uji pemotongan dengan menggunakan follower rest}

1. Uji pemotongan $\mathrm{Kr}=45^{\circ}$

Gambar hasil pemotongan slender bar ST-42 dengan menggunakan pahat potong carbide insert dimana sudut potong utama $\mathrm{Kr}=45^{\circ}$ ditunjukkan pada gambar 7 yaitu tahap mulainya proses pembubutan dan gambar 8 saat terjadi chatter. Parameter proses pembubutan yang digunakan putaran mesin 367 rpm, gerak makan 0,035 $\mathrm{mm} /$ putaran.

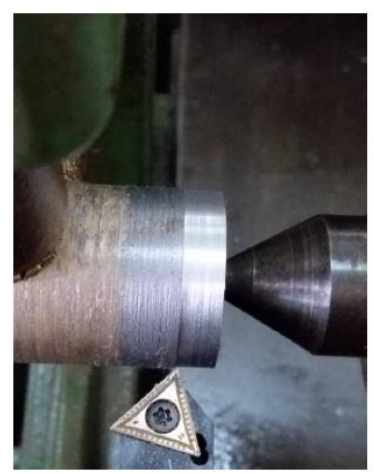

Gambar 7. Hasil Pemotongan Pada Kedalaman Potong $0,2 \mathrm{~mm}$

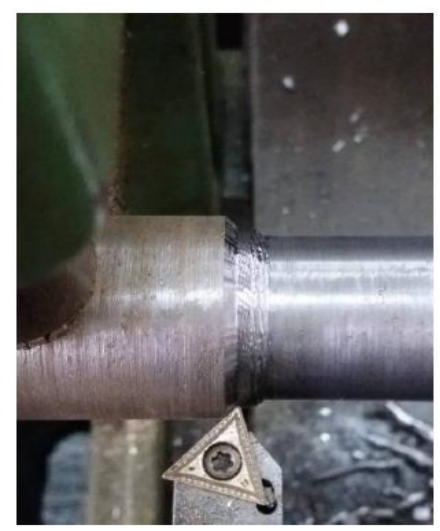

Gambar 8. Hasil Pemotongan Pada Kedalaman Potong 3,2 mm, Terjadi Chatter

\section{Uji pemotongan $\mathrm{Kr}=90^{\circ}$}

Gambar hasil pemotongan slender bar ST-42 dengan menggunakan pahat potong carbide insert dimana sudut potong utama $\mathrm{Kr}=90^{\circ}$ ditunjukkan pada gambar 9 yang merupakan tahap awal proses pembubutan dan gambar 10 saat terjadi chatter. Parameter proses pembubutan yang digunakan putaran mesin $520 \mathrm{rpm}$, gerak makan $0,07 \mathrm{~mm} /$ putaran.

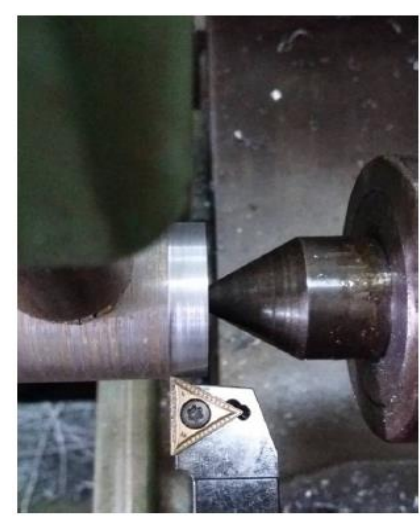

Gambar 9. Hasil Pemotongan Pada Kedalaman Potong $0,2 \mathrm{~mm}$

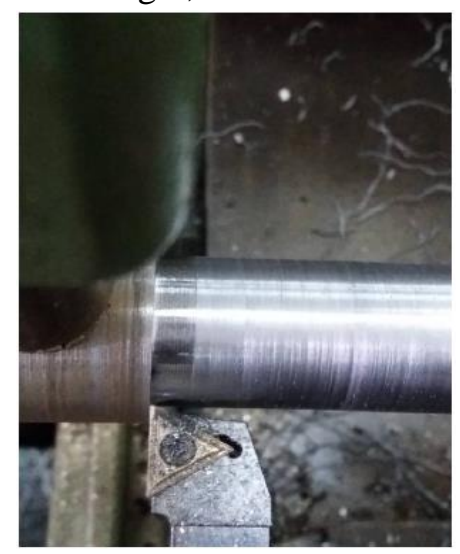

Gambar 8. Hasil Pemotongan Pada Kedalaman Potong 3,0 mm, Terjadi Chatter

\section{Pembahasan}

Elemen dasar dalam proses pembubutan dapat dapat dihitung dengan menggunakan rumus berikut

- Kecepatan potong:

$$
\mathrm{V}=\frac{\pi \cdot \mathrm{d} \cdot \mathrm{n}}{1000}
$$

Untuk $K r=45^{\circ}$ dimana, $\mathrm{d}=$ diameter ratarata benda kerja $=32,8 \mathrm{~mm}$

$$
\mathrm{V}=\frac{\pi \cdot 32,8.367}{1000}=37,8 \mathrm{~m} / \text { menit }
$$

Untuk $\mathrm{Kr}=90^{\circ}$ dimana, $\mathrm{d}=$ diameter ratarata benda kerja $=33,2 \mathrm{~mm}$

$$
\mathrm{V}=\frac{\pi 333,2.520}{1000}=54,2 \mathrm{~m} / \text { menit }
$$

- Kecepatan makan:

$$
\mathrm{V}_{\mathrm{f}}=\mathrm{f} . \mathrm{n}
$$


Untuk $K r=45^{\circ}$ dimana, $\mathrm{f}=0,035$ $\mathrm{mm} /$ putaran

$$
\mathrm{V}_{\mathrm{f}}=0,035.367=12,85 \mathrm{~mm} / \mathrm{menit}
$$

Untuk $K r=90^{\circ}$ dimana, $\mathrm{f}=0,07$ $\mathrm{mm} /$ putaran

$$
\mathrm{V}_{\mathrm{f}}=0,07.520=36,4 \mathrm{~mm} / \mathrm{menit}
$$

Tabel 1 berikut ini adalah nilai kedalaman potong yang menghasilkan chatter pada proses bubut slender bar tanpa follower rest.

Tabel 1. Nilai kedalaman potong terjadinya chatter pada proses bubut slender bar tanpa follower rest

\begin{tabular}{|c|c|c|c|}
\hline $\begin{array}{c}\text { Sudut Potong } \\
\text { Utama }(\mathrm{Kr})\end{array}$ & $\begin{array}{c}\text { Kecepatan Potong } \\
(\mathrm{m} / \mathrm{m} \text {-nit) }\end{array}$ & $\begin{array}{c}\text { Kecepatan Makan } \\
(\mathrm{mm} / \text { menit) }\end{array}$ & $\begin{array}{c}\text { Kedalaman potong } \\
(\mathrm{mm})\end{array}$ \\
\hline $45^{\circ}$ & 37,8 & 12,85 & 2,2 \\
\hline $90^{\circ}$ & 54,2 & 36,4 & 1,8 \\
\hline
\end{tabular}

Sedangkan untuk nilai kedalaman potong yang menghasilkan chatter pada proses bubut slender bar dengan menggunakan follower rest.dapat dilihat pada tabel 2 .

Tabel 2. Nilai kedalaman potong terjadinya chatter pada proses bubut slender bar dengan menggunakan follower rest

\begin{tabular}{|c|c|c|c|}
\hline $\begin{array}{c}\text { Sudut Potong } \\
\text { Utama }(\mathrm{Kr})\end{array}$ & $\begin{array}{c}\text { Kecepatan Potong } \\
(\mathrm{m} / \text { menit) }\end{array}$ & $\begin{array}{c}\text { Kecepatan Makan } \\
(\mathrm{mm} / \text { menit) }\end{array}$ & $\begin{array}{c}\text { Kedalaman potong } \\
(\mathrm{mm})\end{array}$ \\
\hline $45^{\circ}$ & 37,8 & 12,85 & 3,2 \\
\hline $90^{\circ}$ & 54,2 & 36,4 & 3,0 \\
\hline
\end{tabular}

Darı tabel diatas dapat dilıhat bahwa penggunaan follower rest dapat meningkatkan kedalaman potong pada proses bubut slender bar sebesar $45,45 \%$ dengan parameter pemesinan sudut potong utama $\mathrm{Kr}=45^{\circ}$, kecepatan potong $37,8 \mathrm{~m} / \mathrm{menit}$ dan kecepatan makan $12,85 \mathrm{~mm} /$ menit.

Selain itu penggunaan follower rest juga dapat meningkatkan kedalaman potong pada proses bubut slender bar sebesar 66,67\% dengan parameter pemesinan sudut potong utama $\mathrm{Kr}=90^{\circ}$, kecepatan potong 54,2 $\mathrm{m} / \mathrm{menit}$ dan kecepatan makan 36,4 mm/menit.

\section{KESIMPULAN DAN SARAN Kesimpulan}

Berdasarkan pada hasil analisis dan pembahasan pada bab sebelumnya, dapat disimpulkan beberapa hal berkaitan dengan proses bubut slender bar dengan dimensi $\varnothing 35$ $\mathrm{mm}$ dan panjang $800 \mathrm{~mm}$.

1. Pada proses bubut slender bar tanpa follower rest, chatter terjadi pada kedalaman potong 2,2 $\mathrm{mm}$ dengan sudut potong utama $\mathrm{Kr}=45^{\circ}$, kecepatan potong $37,8 \mathrm{~m} /$ menit dan kecepatan makan 12,85 $\mathrm{mm} / \mathrm{menit}$.

2. Pada proses bubut slender bar tanpa follower rest, chatter terjadi pada kedalaman potong $1,8 \mathrm{~mm}$ dengan sudut potong utama $\mathrm{Kr}=90^{\circ}$, kecepatan potong $54,2 \mathrm{~m} /$ menit dan kecepatan makan 36,4 $\mathrm{mm} / \mathrm{menit}$.

3. Pada pemotongan menggunakan follower rest, chatter terjadi pada kedalaman potong 3,2 $\mathrm{mm}$ dengan sudut potong utama $\mathrm{Kr}=45^{\circ}$, kecepatan potong $37,8 \mathrm{~m} /$ menit dan kecepatan makan $12,85 \mathrm{~mm} /$ menit.

4. Pada pemotongan menggunakan follower rest, chatter terjadi pada kedalaman potong $3,0 \mathrm{~mm}$ dengan sudut potong utama $\mathrm{Kr}=$ $90^{\circ}$, kecepatan potong $54,2 \mathrm{~m} /$ menit dan Saran kecepatan makan $36,4 \mathrm{~mm} /$ menit.

Pada proses bubut slender bar ini belum memasukkan penggunaan sistem peredam spring-mass damper pada follower rest. Sehingga pada penelitian berikutnya diharapkan dapat memasukkan penggunaan sistem peredam spring-mass damper guna memperkaya dan mengembangkan hasil penelitian ini

\section{DAFTAR PUSTAKA}

Cheng, C. C., Kuo, C. P., dan Cheng, W. N. (2009), "Moving Follower Rest Design Using Vibration Absorbers For Ball Screw Grinding," Journal of Sound and Vibration, Vol. 326, hal 123-136.

Jianliang, dan Rongdi, Han (2006), “A United Model of Diametral Error in Slender Bar Turning with a Follower Rest," International Journal of Machine Tools \& Manufacture, Vol. 46, hal. 10021012.

Kalpakjian, S. dan Schmid, S. R. (2001), Manufacturing Engineering and Technology, $4^{\text {th }}$ edition, Prentice Hall, New York.

Membala, S. B. (2013), Studi Eksperimen Pengaruh Pengisian Pasir Pada Proses 
Bubut Eksternal Pipa Baja Seamless Untuk Pencekaman Dalam Dan Luar

Terhadap Batas Stabilitas, Tesis

Teknik Mesin, Institut Teknologi Sepuluh Nopember, Surabaya.

Rochim, Taufiq (1993). Teori dan Teknologi

Proses Pemesinan, Institut Teknologi

Bandung, Bandung.

Suhardjono (2000), Ein Variabel Einsetzbarer

Gedämpfter Tilger zur Reduzierung von

Ratterschwingungen

bei

Drehmaschinen, Wissenschaft \&

Technik Verlag, Berlin. 